\title{
Manual de Trabalhos Laboratorials de Química Orgânica E FARMACÊUTICA
}

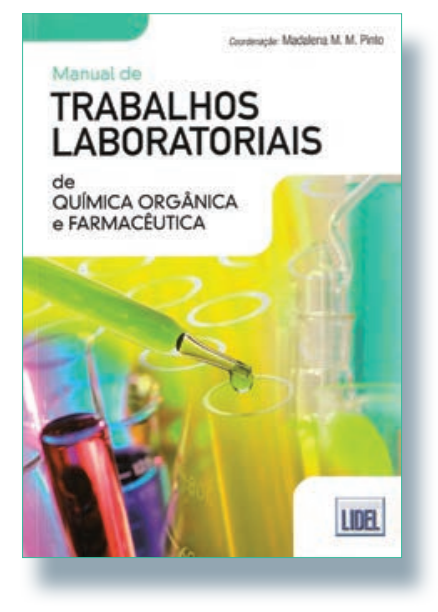

O presente volume é fruto da experiência pedagógica de um grupo de docentes do Laboratório de Química Orgânica e Farmacêutica da Faculdade de Farmácia da Universidade do Porto. Está claramente pensado como suporte à componente experimental de cursos universitários das áreas de Química Farmacêutica e Medicinal, embora seja de inegável utilidade em cursos introdutórios de Técnicas Laboratoriais e de Química Orgânica. Poderá também servir como obra de apoio a professores do ensino secundário das áreas de Química e Ciências da Saúde, que frequentemente se deparam com a escassez de material adequado em língua portuguesa.

Uma componente substancial da obra é dedicada à apresentação dos critérios básicos de pureza de compostos orgânicos (pontos de fusão e ebulição, espectro de infravermelho em comparação com o de um padrão, cromatografia analítica, índice de refração, densidade e rotação específica), processos de purificação (extração, destilação, sublimação, cristalização e cromatografia) e critérios de identificação de substâncias orgânicas (desde

\footnotetext{
* Departamento de Engenharia Química

E-mail: matilde.marques@ist.utl.pt
}

\author{
M. Matilde Marques*
}

\author{
Coordenação: Madalena M. M. Pinto \\ Editora: Lidel - Edições Técnicas, Lda \\ N. ${ }^{\circ}$ páginas: 484 * ISBN: 978-972-757-750-7
}

a análise elementar à identificação de grupos funcionais e à caracterização estrutural por via espectroscópica, com ênfase em ultravioleta-visível, infravermelho, ressonância magnética nuclear e espectrometria de massa). Os protocolos experimentais propostos são antecedidos de textos introdutórios, necessariamente sucintos, complementando-se a informação no fim de cada subcapítulo com referências bibliográficas adequadas. São de louvar a inclusão de um subcapítulo sobre extração em fase sólida, frequentemente ausente de manuais de laboratório clássicos, bem como a inclusão de informação relativa aos fundamentos da cromatografia líquida de alta eficiência (HPLC) e da cromatografia gasosa.

$\mathrm{Na}$ segunda parte do manual são propostos vários trabalhos laboratoriais essencialmente orientados para Química Farmacêutica. Os protocolos são geralmente simples mas selecionados de modo criterioso para utilizar as técnicas de separação e análise introduzidas na primeira parte. O foco centra-se na síntese, isolamento, análise e doseamento de substâncias biologicamente ativas. Aplaude-se a inclusão de um conjunto de protocolos de natureza inovadora em manuais deste tipo, que abordam conceitos frequentemente tratados a nível teórico em cursos de Química Medicinal, mas raramente ilustrados experimentalmente. Estão neste caso, por exemplo, a determinação de coeficientes de partição e a sua utilização para obter constantes lipofílicas de substituintes, a utilização de modelos químicos para avaliar a influência do $\mathrm{pH}$ na absorção de fármacos, a abordagem experimental ao conceito de reconhecimento molecular (essencial nas interações ligando-recetor) e a introdução ao planeamento de fármacos assistido por computador.

O livro é completado com um conjunto de anexos úteis, incluindo normas gerais e procedimentos de segurança, generalidades sobre material de laboratório e estrutura das farmacopeias. A consulta é fácil, a informação fornecida é correta e equilibrada e a qualidade gráfica é excelente. Em resumo, trata-se de um manual de qualidade, com aspetos inovadores, cujo sucesso se antecipa junto de docentes e alunos de Química Orgânica e Farmacêutica em Portugal e (se adequadamente divulgado) em países lusófonos.

\section{$\bigcup_{\substack{\text { SOCIEDADE } \\ \text { PORTUGUSA }}}$ \\ SPQ - Há 100 anos a divulgar a Química em Portugal \\ Viste a nossa homepage em www.spq.pt e esteja sempre atualizado \\ Torne-se sócio e usufrua de muitos benefícios}

